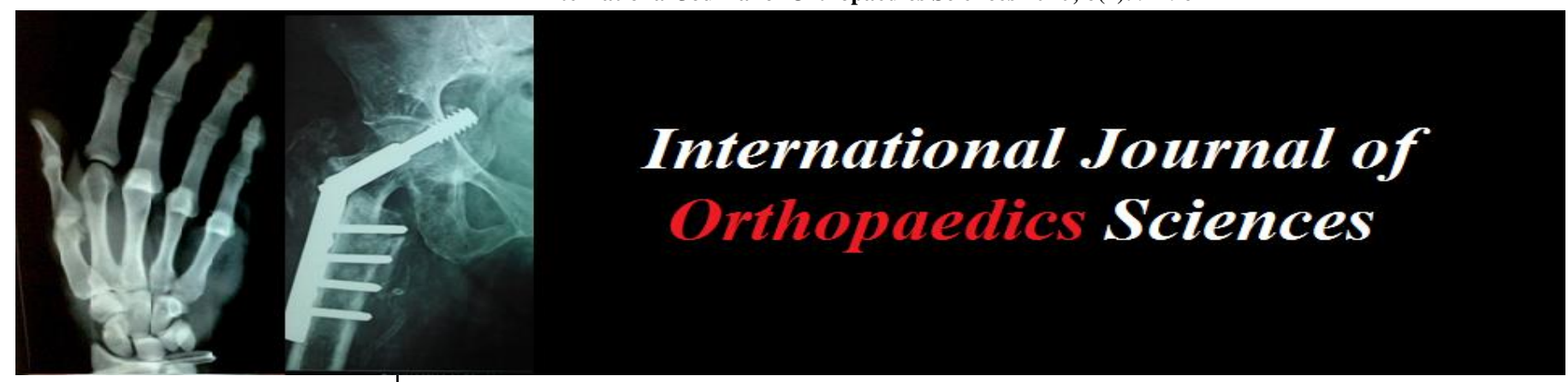

E-ISSN: 2395-1958

P-ISSN: 2706-6630

IJOS 2020; 6(1): $92-96$

(C) 2020 IJOS

www.orthopaper.com

Received: 24-11-2019

Accepted: 26-12-2019

Dr. Yogesh C Patel

Associate Professor and Head of

Unit, Department of

Orthopaedics, SSG Hospital and

Medical College Baroda,

Vadodara, Gujarat, India

Dr. Vihal D Patel

Resident Doctor, Department of Orthopaedics, SSG Hospital and Medical College Baroda,

Vadodara, Gujarat, India

\section{A study of anterior bridge plating with MIPO technique for fracture shaft humerus}

\author{
Dr. Yogesh C Patel and Dr. Vihal D Patel
}

DOI: https://doi.org/10.22271/ortho.2020.v6.i1b.2054

\section{Abstract}

Introduction: Shaft humerus fracture is one of the most common fracture in our newly developed world. Wide range of treatment modalities available from conservative to nailing and plating. Our study done to evaluate the clinical, radiological, and functional outcome of such fractures in 20 patients with anterior bridge plating with MIPO technique. Though open reduction and plating technique of humerus shaft fracture is gold standard, this technique also gives good outcome.

Materials and methods: A prospective study of anterior bridge plating ith MIPO technique was carried out at our institute, at the Department of Orthopaedics, S.S.G. hospital Vadodara between November 2018 and July 2019, were 20 patients of shaft hmerus fracture selected after applying inclusion and exclusion criteria. Fracture s were classified as per AO classification. Assessment of union, movement at shoulder and elbow joint, Quick DASH score and complications were done during regular follow up of 4 month.

Results: In our study, after clinical and radiological assessment after 4 monthh follow up,out of the 20 patients in the study, 16 were males and 4 were females. The mean age was 42.35 years (range 19 to 63 years). The mean fracture union (radiological) time was 13.5 weeks (range: 10-16 weeks). According to quick DASH score 18(90\%) patients has excellent result and remaining 2(10\%) patients had good results. Conclusion: There is high rate of union and excellent functional outcomes by this procedure. It is concluded from the study that close reduction with internal fixation with anterior bridge plating \& MIPO technique is an excellent mode of treatment for shaft humerus fracture which constantly give long term good result with less complication and early postoperative mobilization.

Keywords: Anterior bridge plate, Shaft humerus fracture, quick DASH score,surgical management and functional outcome

\section{Introduction}

The conflict between the need for absolute anatomical reduction and, at the same time, the desire for soft tissue preservation has been going on for a long time. Not just solid healing but immediate and continuous function of limb is now a leading goal. However, precise reduction and absolute stable fixation has its biological price. There has been evidence to superiority biological fixation over stable mechanical fixation. This lead to development and improvement in the technique of biological fixation for fractures and also the development of stabilization systems that helps in achieving the biological fixation. From conservative cast and braces to internal fixation with intramedullary interlocking nailing, ORIF with plate and screw. Treatment of humeral fracture has evolved a lot with their complications. Studies are still going on to prove superiority of one over another. Minimally invasive technique for humerus shaft fracture has shown promising results recently. This study have evaluated the clinical, radiological, and functional outcomes of this mini invasive technique for humerus fracture over a minimum follow-up of 4 months.

\section{Material and methods}

A prospective study of treatment of shaft humerus fractures treated with anterior bridge plating with MIPO technique was carried out at our institute, at the Department of Orthopaedics, S.S.G. Hospital Vadodara from November 2018 to august 2019, where after applying exclusion and inclusion criterion, 20 patients of shaft humerus fractures were included in our

\section{Dr. Yogesh C Patel}

Associate Professor and Head of

Unit, Department of

Orthopaedics, SSG Hospital and

Medical College Baroda,

Vadodara, Gujarat, India 
study. Before including them in this study, informed consent was obtained from them in the language in which they were well suited, and ethical committee clearance was obtained for the same.

\section{Criteria for patient selection}

1. Adults above the age of 18 years

2. Fresh fracture with or without neurovascular deficit

3. Close fracture, fracture with open Grade I and II were also included.

4. Fractures of shaft humerus of AO class A and B are included in study.

\section{Exclusion criteria}

1. Pathological fracture

2. Malunited fracture

3. Infected fracture

4. Poor general (medical) condition (where patient cannot tolerate the surgery)

5. Open fracture (grade III)

\section{Treatment protocol}

All the patients were treated according to protocol which consisted of:-

1. Standard A.P. \& lateral plain X-ray.

2. Open wound were taken to operation theatre for wound debridement on emergency basis as early as possible.

3. Poly trauma patients were fixed as soon as their general condition allowed for surgery.

4. Shoulder range of movement and elbow range of movement exercises started according implant used and stability of fixation of fracture, post operatively.
5. Patients discharged with AE slab or humerus brace depending on stability of fixation.

6. Weight lifting and routine work, is allowed according to union status radiologically and clinically.

7. Patients follow up depended on the clinical examination as well as the xray findings.

- Fractures were classified according to AO's classification for operative planning and further management of the fracture.

\section{Surgical technique}

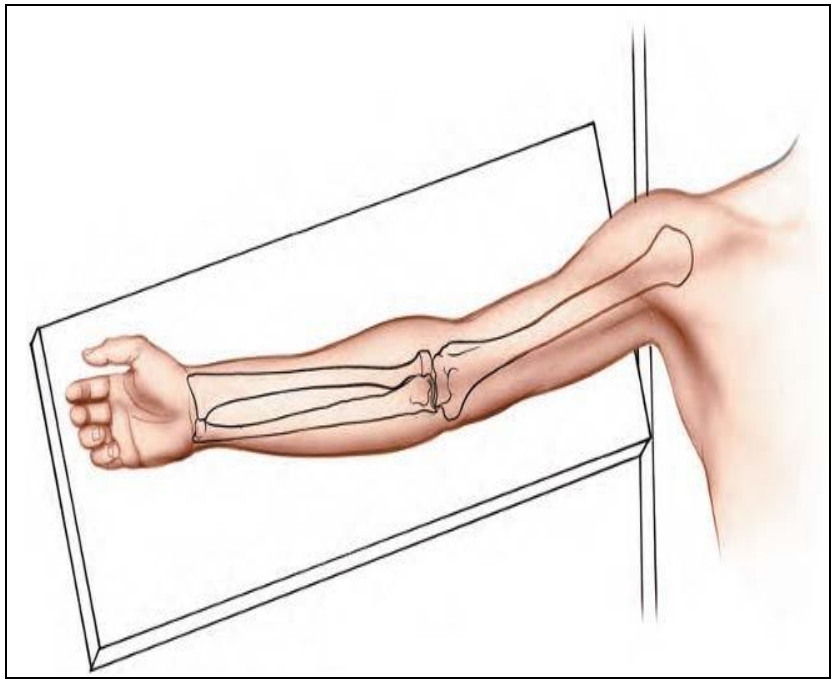

\section{Position of patient}

A

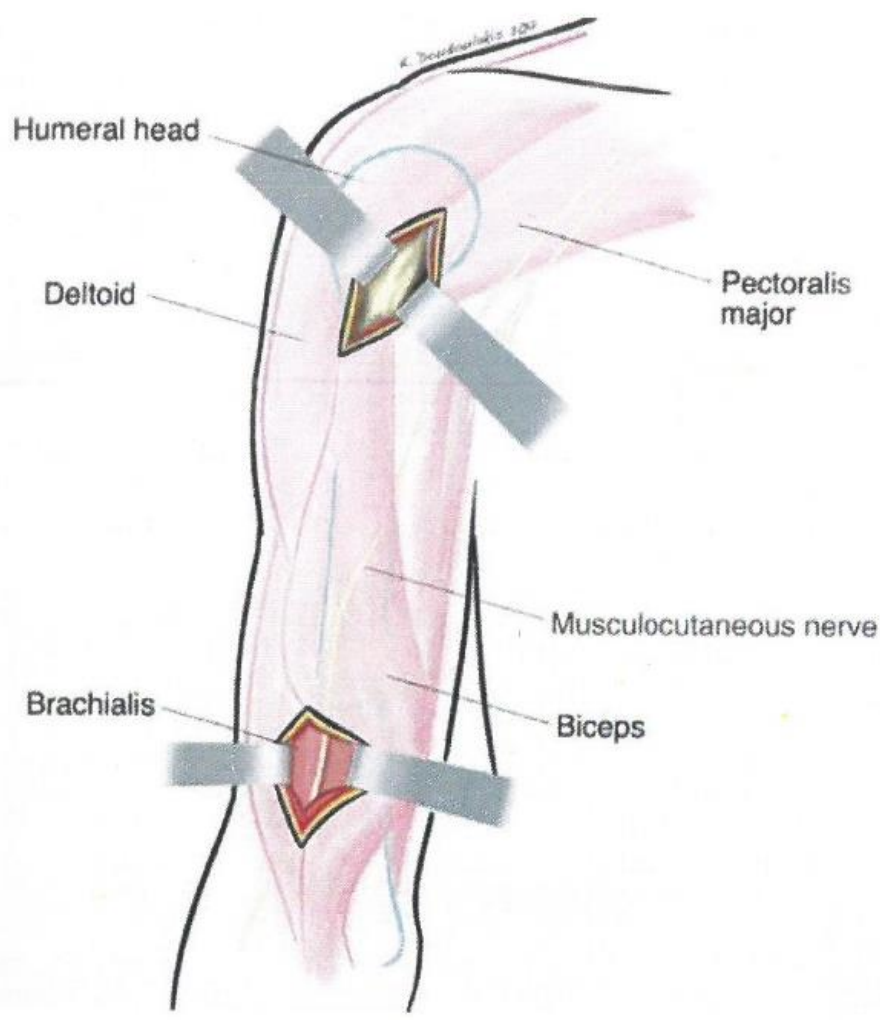

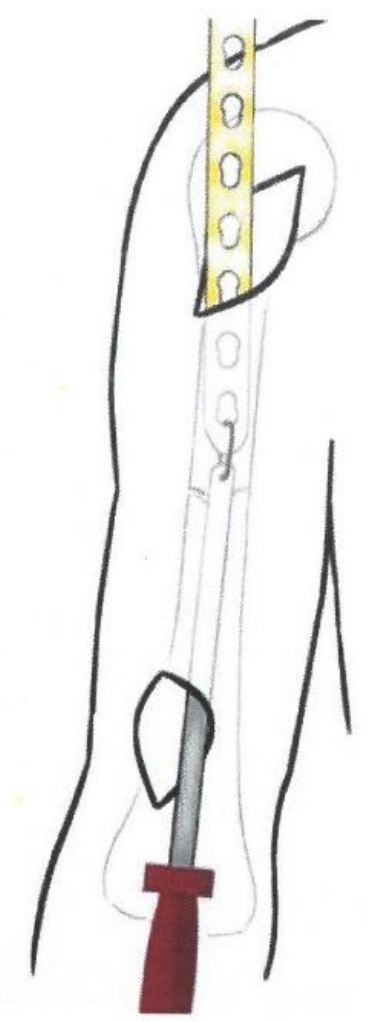

\section{Osteosynthesis}

A: The proximal and distal windows.
B: Insertion of the plate is facilitated with the use of a tunneling instrument. 


\section{Position of patient}

- Place patient in supine position.

\section{Landmarks}

Palpate coracoid process of scapula and lateral border of bisceps.

\section{Incision}

Make 3-5cm long incision beginning just below coracoid process running down arm in line of delto-pectoral groove Make another incision of about $3-5 \mathrm{~cm}$ longitudinally over lateral brder of biscepsbrachii in distal third of arm.

\section{Intervenous plane}

Proximally, the anterior minimal access approach utilizes plane between deltoid muscle and pectoralis major muscle. Distally, the plane lies between medial half of brachialis muscle and lateral half of brachialis muscle.

\section{Superfecial dissection}

\section{Proximal window}

Identify delto-pectoral groove, using cephalic vein as a guide. Seperate two muscles.

\section{Distal window}

Incise deep fascia of arm in line of skin incision and identify muscular interval between biscepsbrachii and brachialis.

Develop this interval by retracting bisceps medially and identify brachialis muscle covering anterior humeral shaft.

\section{Deep surgical dissection \\ Proximal window}

Develop plane between deltoid and pectoalis major down to bone.

Stay lateral to tendon of long head of bisceps.

Detatch some part of insertion of pectoralis major and deloid for easier plate application.

\section{Distal window}

Split fibres of brachialis longitudinally and develop epiperiosteal plane between deep surface of brachialis and periosteum.

Flex relbow to reduce tension on brachialis muscle. To connect two windows, develop epiperiosteal plane on anterior surface of humerus using blunt elevator.

Begin distally and stick closely to bone's anterior surface.

\section{Plating}

After dissection tunnel was made with cobbs elevator. The shoulder was abducted to $30^{\circ}-60^{\circ}$, the elbow was flexed to about $90^{\circ}$, and the forearm is supinated throughout the procedure. Indirect reduction manoeuvres were used when needed for optimal fracture reduction. The longest possible $4.5 \mathrm{~mm}$ dynamic/locking compression plate (DCP/LCP) was chosen depending on the humeral anatomy. During insertion of the distal screws on the anterior surface, care was taken to the proximity of the radial nerve laterally and brachial artery and musculocutaneous nerve medially.

\section{Observation and Results}

This study includes 20 patients of fractures shaft humerus treated with close reduction and anterior bridge plating with MIPO technique. Patient operated from November 2018 to August 2019 were taken in our study.

Out of 20 patients, 16 were male and 4 were female. The mean age was 42.5 years(Range 19-63 years), among them $10(50 \%)$ were injured due to RTA, $8(40 \%)$ injured due to fall from height and $2(10 \%)$ due to assault.

Out of 20 patient, $18(90 \%)$ patients had excellent result and 2 (10\%) had good result, among them 19(95\%) patients were able to resume their pre-trauma occupation.

\section{Mode of injury}

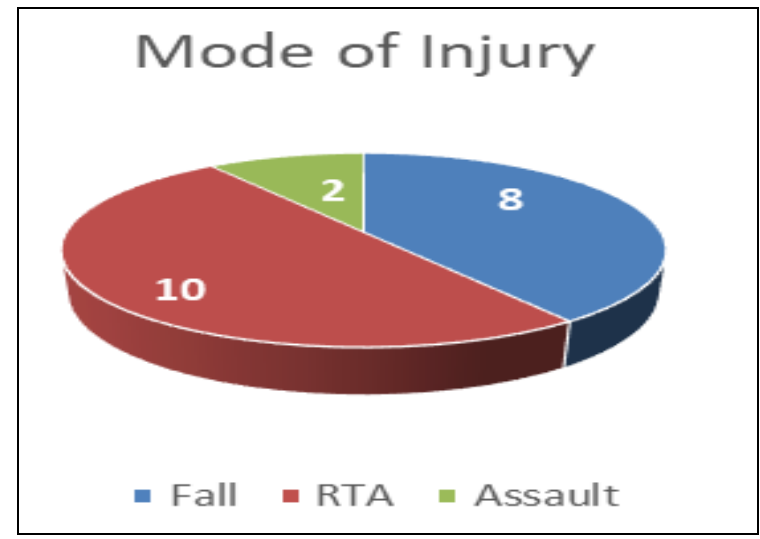

- Most of patients had sustained fracture with RTA.

- In our study it comprises 10 patients (50\%), whereas 2 patients had assault injury.

\section{Time taken for union}

\begin{tabular}{|c|c|c|}
\hline Duration (weeks) & Patients & Percentage (\%) \\
\hline $10-12$ & 6 & 30 \\
\hline $12-14$ & 8 & 40 \\
\hline $14-16$ & 6 & 30 \\
\hline Total & 20 & 100 \\
\hline
\end{tabular}

- $\quad 14(70 \%)$ fracture united between 12-14 weeks.

- $10(30 \%)$ fracture united between 14-16 weeks.

- Average time for union is 13.5 weeks.

\section{Complications}

\begin{tabular}{|c|c|c|}
\hline Complication & Patients & Percentage (\%) \\
\hline Non union & 0 & 0 \\
\hline Mal union & 0 & 0 \\
\hline Implant failure & 0 & 0 \\
\hline Implant Loosening & 0 & 0 \\
\hline Joint Stiffness & 2 & 10 \\
\hline Infection & 2 & 10 \\
\hline
\end{tabular}

- $\quad 2(10 \%)$ patients having joint stiffness.

- $2(10 \%)$ patients (case no.4 \&15) having superficial infection. No deep infection and no osteomyelitis seen in our study.

\section{Classification of fracture with result}

\begin{tabular}{|c|c|c|c|}
\hline Type & Sub type & Excellent & Good \\
\hline \multirow{3}{*}{ Simple } & A1-simple spiral & $2(15 \%)$ & $1(5 \%)$ \\
\cline { 2 - 4 } & A2-simple oblique $\left(\geq 30^{\circ}\right)$ & $7(35 \%)$ & - \\
\cline { 2 - 4 } & A3-simple transverse $\left(<30^{\circ}\right)$ & $7(35 \%)$ & - \\
\hline \multirow{3}{*}{ Wedge } & B1-spiral wedge & - & - \\
\cline { 2 - 4 } & B2-bending wedge & $2(10 \%)$ & $1(5 \%)$ \\
\cline { 2 - 4 } & B3-Fragmented wedge & - & - \\
\hline \multirow{3}{*}{ Complex } & C1-Complex spiral & - & - \\
\cline { 2 - 4 } & C2-complex segmental & - & - \\
\cline { 2 - 4 } & C3-complex irregular & - & - \\
\hline
\end{tabular}


- Allmost A1 and A2 variety showed excellent result because of spiral and oblique fracture configuration which increased contact area.

- Good result found in one A1 type fracture and one B2 fracture in our study.

\section{Excellent result}

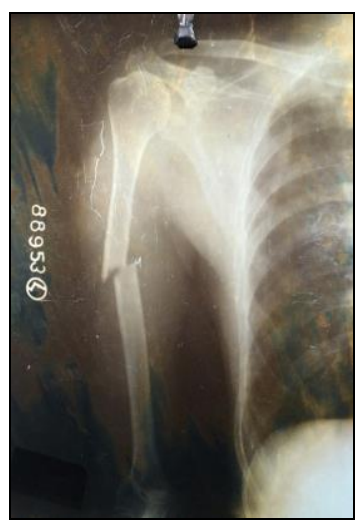

Pre - op AP

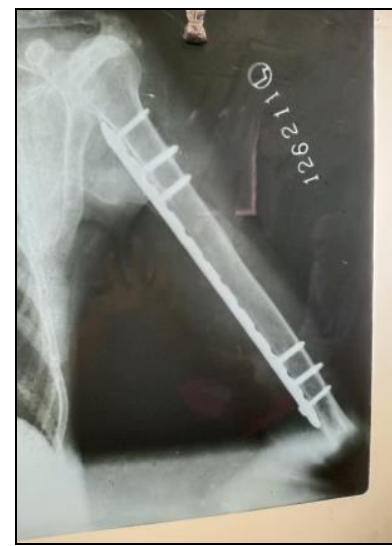

Post - op AP

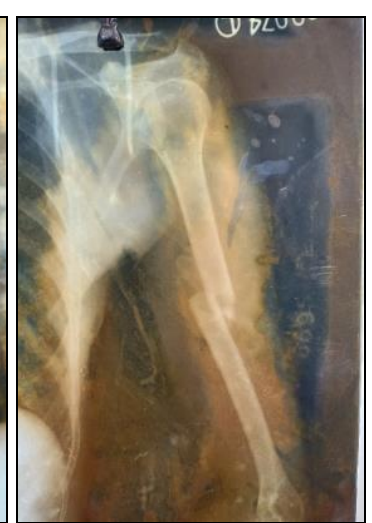

Pre - op Lateral

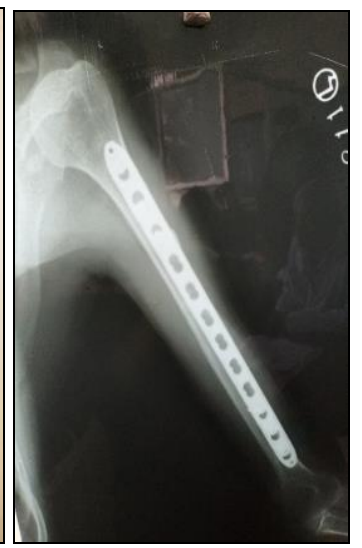

Post - op Lateral
Final Follow - up (4 months)
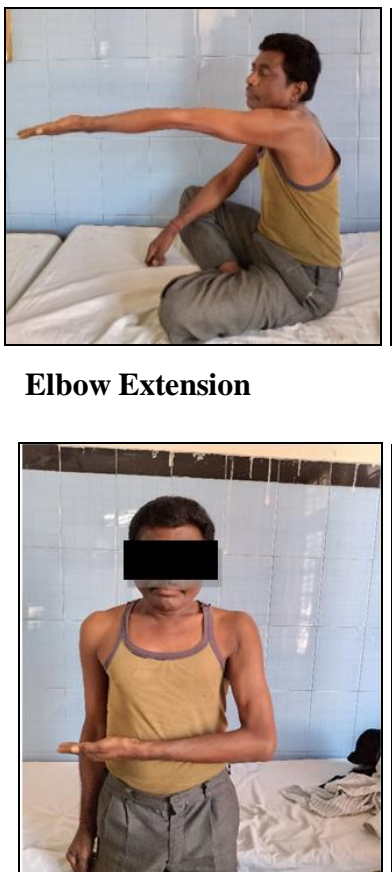

Internal Rotation
Elbow Extension

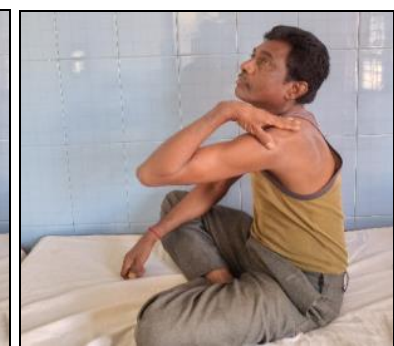

Elbow flexion

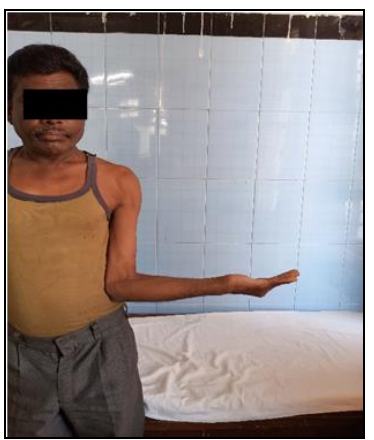

External Rotation

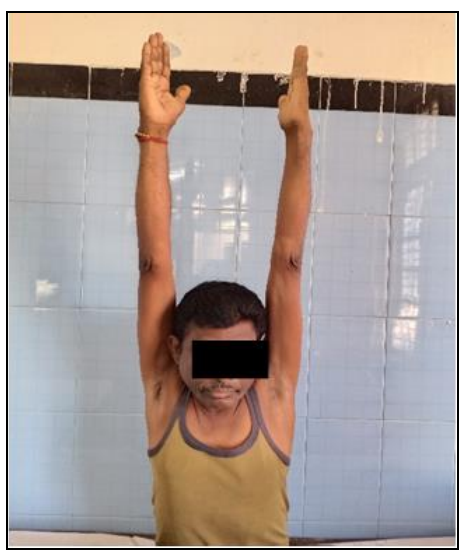

Shoulder overhead abduction

\section{Discussion \& analysis}

Fracture of shaft of humerus consists of $1 \%$ of all fracture. It is a common fracture of upper limb fractures of shaft of humerus are increasing in frequency day due to rising population and modernization. Numbers of multiple injured patients having fracture of shaft of humerus are also increasing as are open fractures of humerus especially alter vehicular accidents and work place injuries.

The study of fracture of shaft of humerus is important due to chances of these fractures to go in malunion (in closed fracture) and (in open fractures) are more. The functional disability to the patient alter these fractures is a hindrance in earning their daily living especially when dominant extremity involved.

Tscherne and Krettek first reported minimal invasive osteosynthesis for fractures in 1996. Since then this technique is used in managing various other fractures. Despite the requirement of high surgical expertise and time taken for adaptation of the procedure, the MIPO technique seems to be reproducible and applicable in almost all types of shaft humeral fractures. Lower rates of iatrogenic nerve injury with minimal bone vascularity disruption, and soft tissue dissection are all the advantages over conventional plate technique.

Life is movement and movement is life. For active, pain free mobilization results in a rapid return to normal blood supply to both bone and soft tissue. This is the AO's main objective and is better achieved by a stable rigid plate osteosynthesis.

Now after facing problems of nailing and compression plating new method emerged call anterior bridge plating, in which plate fixation done under close reduction. Anterior bridge plating with MIPO technique has its own advantages and disadvantages.

\section{Advantages}

1. Small size incision

2. Less blood loss and less amount of tissue damage

3. Less chance of infection

4. Less chance of radial nerve palsy

5. Less chance of non union because it is a close reduction procedure so no callus destruption at fracture site which provides good union.

6. Restriction of shoulder movement is negligible.

7. Due to rigid fixation early mobilisation is possible.

8. Not require large set of instrumentation so cost effective

Thus, analysis of the results of this study shows factors affecting results are

Stable internal fixation /early Mobilization: Good surgical 
technique, precise anatomical reduction, stable internal fixation and early mobilization had given good results.

Line of management: With better fixation devices, improved operative techniques and antibiotics, we obtained acceptable results.

Type of trauma / fracture: Soft tissue damage and associated bone necrosis increased time for healing. Associated injury to vital structures had caused delay in fixation and finally poor results.

\section{Conclusion}

Close reduction with internal fixation with anterior bridge plating with MIPO technique gives precise anatomical reduction and stable fixation at fracture site hence leading to early mobilization of patient post operatively. This technique is an excellent mode of treatment for shaft humerus fracture which constantly give long term good result with less complication.

\section{Reference}

1. Frigg R, Wagner M. AO Manual of fracture management. Chapters 1.2: Concepts of fracture fixation, 2006.

2. Dickson KF, Munz JW. Biomechanics and biology of Locked plating: Tech Orthop, 2007; 22:4.

3. Angelini AJ, Livani B, Flierl MA, Morgan SJ, Belangero WD. Less invasive percutaneous wave plating of simple femur shaft fractures. A prospective series. Int Orthop. 2010; 41(6):624-8.

4. Heitemeyer U, Claes L, Hierholzer G, Körber M. Significance of postoperativestability for bony reparation of comminuted fractures. An experimental study. Arch Orthop Trauma Surg. 1990; 109(3):144-9.

5. Gerber C, Mast JW, Ganz R. Biological internal fixation of fractures. Arch Orthop Trauma Surg. 1990; 109(6):295-303.

6. Miclau T, Martin RE. The evolution of modern plate osteosynthesis. Injury. 1997; 28(1):A3-6.

7. Farouk O, Krettek C, Miclau T, Schandelmaier P, Guy P, Tscherne H. Minimally invasive plate osteosynthesis and vascularity: preliminary results of a cadaver injection study. Injury. 1997; 28(1):A7-12.

8. Perren SM. Evolution of the internal fixation of long bone fractures. The scientific basis of biological internal fixation: choosing a new balance between stability and biology. J Bone Joint Surg Br. 2002; 84(8):1093-110.

9. Livani B, Belangero WD. Bridging plate osteosynthesis of humeral shaft fractures. Injury. 2004; 35(6):587-95.

10. Apivatthakakul T, Arpornchayanon O, Bavornratanavech S. Minimally Invasive plate osteosynthesis (MIPO) of the humeral shaft fracture. Is it possible? A cadaveric study and preliminary report. Injury. 2005; 36(4):530-8.

11. Apivatthakakul T, Patiyasikan S, Luevitoonvechkit S. Danger zone for locking screw placement in minimally invasive plate osteosynthesis (MIPO) of humeral shaft fractures: a cadaveric study. Injury. 2010; 41(2):169-72.

12. Livani B, Belangero WD, Castro de Medeiros R. Fractures of the distal third of the humerus with palsy of the radial nerve: management usingn minimally-invasive percutaneous plate osteosynthesis. J Bone Joint Surg Br. 2006; 88(12):1625-8.

13. Ziran BH, Belangero W, Livani B, Pesantez R. Percutaneous plating of the humerus with locked plating: technique and case report. J Trauma. 2007; 63(1):205-10.

14. Schwarz N, Windisch M, Mayr B. Minimally Invasive anterior plate osteosynthesis in humeral shaft fractures.
Eur J Trauma Emerg Surg. 2009; 35(3):271-6.

15. Concha JM, Sandoval A, Streubel PN. Minimally invasive plate osteosynthesis for humeral shaft fractures: are results reproducible? Int Orthop. 2010; 34(8):1297305.

16. Hudak PL, Amadio PC, Bombardier C. Development of an upper extremity outcome measure: the DASH (disabilities of the arm, shoulder and hand) [corrected]. The Upper Extremity Collaborative Group (UECG). Am J Ind Med. 1996; 29(6):602-8.

17. Thompson. e Henry (1924 e 1966) - The humerus in: Hoppenfeld S., De Boer P. Surgical Exposures in Orthopaedics, The anatomic Approach 3rd Ed;2003, Charpter. 1918; 2:67-103

18. Livani B, Belangero WD. Osteossíntese de fratura diafisária do úmero com placa em ponte: apresentação e descrição da técnica. Acta Ortop Bras. 2004; 12(2):113-7.

19. Gustilo RB, Anderson JT. Prevention of infection in the treatment of one thousand and twenty-five open fractures of long bones: retrospective and prospective analyses. J Bone Joint Surg Am. 1976; 58(4):453-8.

20. Gustilo RB, Mendoza RM, Williams DN. Problems in the management of type III (severe) open fractures: a new classification of type III open fractures. J Trauma. 1984; 24(8):742-6.

21. Benegas E, Amódio DT, Correia LFM, Malavolta EA, Ramadan LB, Ferreira Neto AA et al. Estudo comparativo prospectivo e randomizado entre o tratamento cirúrgico das fraturas diafisárias do úmero com placa em ponte e haste intra medular bloqueada (analise preliminar). Acta Ortop Bras. 2007; 15(2):87-92.

22. Kobayashi M, Watanabe Y, Matsushita T. Early full range of shoulder and elbow motion is possible after minimally invasive plate osteosynthesis for humeral shaft fractures. J Orthop Trauma. 2010; 24(4):212-6.

23. Rodrigo Kallas Zogaib, Steven Morgan, Paulo Santoro Belangero, Helio Jorge Alvachian Fernandes, Willian Dias Belangero, Bruno Livani. Minimal invasive ostheosintesis for treatment of diaphiseal transverse humeral shaft fracture. Acta Ortop bras. 2014; 22(2):94-8 